\title{
The relation between adult height and haemorrhagic and ischaemic stroke in the Renfrew/Paisley study
}

\author{
P McCarron, C L Hart, D Hole, G Davey Smith
}

Adult height is a useful marker of fetal growth, growth and nutrition in childhood and childhood infections. Studies reporting inverse associations between height and stroke therefore provide support for the hypothesis that exposures acting in early life are important determinants of risk of stroke. ${ }^{12}$ However, few studies have been able to examine the association between height and stroke subtype. We recently showed that height is inversely related to ischaemic stroke, but because of small numbers it was not possible to robustly analyse the association between height and haemorrhagic stroke. ${ }^{1}$ A Norwegian study has shown a stronger inverse association with haemorrhagic compared with ischaemic stroke, but adjustment for socioeconomic position was not possible. $^{2}$ We recently reported a significant inverse association between height and stroke mortality in both men and women in the Renfrew/Paisley cohort. ${ }^{3}$ Here we examine the association between height and subtype of incident stroke in this cohort.

\section{Methods}

The Renfrew/Paisley study, carried out between 1972 and 1976, involved 15406 (almost $80 \%$ ) residents aged 45-64 years from the towns of Renfrew and Paisley. Participants were representative of the population of the west of Scotland. Full details are available elsewhere. ${ }^{4}$ Data collected included height, blood pressure, plasma cholesterol, smoking habit, occupational social class and past medical history. A computerised linkage of hospital admissions in Scotland provided records of main diagnoses of stroke over a 20 year follow up period. After omitting participants with missing data, 15393 people were included in the analyses. Height quintiles were calculated separately for men and women with height groups formed by taking each fifth as the corresponding fifth for men and women respectively. Strokes were classified as ischaemic or haemorrhagic (see table 1). Cox's proportional hazards models were used to calculate relative rates for height quintiles, and per $10 \mathrm{~cm}$ increase in height. There were no significant interactions between height and sex for each type of stroke, so data for men and women were analysed together. Additional adjustment was made for other risk factors for stroke.

\section{Results}

There were 1027 participants with a main discharge diagnosis of stroke of which 239 $(23.3 \%)$ were classified as ischaemic and 90 $(8.8 \%)$ as haemorrhagic. The remaining 698 strokes $(68 \%)$ were ill defined. We found an inverse association between height and all stroke and ill defined stroke (table 1) while for haemorrhagic strokes there was a stronger inverse relation, each $10 \mathrm{~cm}$ increment in height resulting in an almost $30 \%$ decline in risk. The association between height and ischaemic stroke was weak and did not reach statistical significance. The difference between the relative rates for haemorrhagic and ischaemic stroke adjusted for age and sex was not statistically significant $(p=0.29)$. Adjustment for confounding variables had little effect on the relative rates and did not account for the
Accepted for publication 1 February 2001

as hospital discharge with a main diagnosis of stroke)

\begin{tabular}{|c|c|c|c|c|c|c|c|}
\hline \multirow[b]{2}{*}{ For men } & \multicolumn{5}{|c|}{ Height quintile $(\mathrm{cm})$} & \multirow[t]{2}{*}{ Trend } & \multirow[t]{2}{*}{$\begin{array}{l}R R \text { associated with } 10 \\
\mathrm{~cm} \text { increase in height }\end{array}$} \\
\hline & $\leqslant 163$ & $164-167$ & $168-170$ & $171-174$ & $\geqslant 175$ & & \\
\hline For women & $\leqslant 152$ & $153-155$ & $156-158$ & $159-162$ & $\geqslant 163$ & & \\
\hline Number & 2919 & 2737 & 2911 & 3483 & 3343 & & \\
\hline Number of strokes & 241 & 210 & 192 & 210 & 174 & & \\
\hline Relative rate ${ }^{\star}$ & 1 & $0.96(0.80$ to 1.15$)$ & $0.82(0.68$ to 1.00$)$ & $0.77(0.64$ to 0.93$)$ & $0.70(0.57$ to 0.85$)$ & $\mathrm{p}<0.0001$ & $0.80(0.73$ to 0.88$)$ \\
\hline $\begin{array}{l}\text { Relative rate† } \\
\text { Haemorrhagic\$ }\end{array}$ & 1 & $0.98(0.81$ to 1.18$)$ & $0.86(0.71$ to 1.05$)$ & $0.81(0.67$ to 0.97$)$ & 0.73 (0.60 to 0.89$)$ & $\mathrm{p}=0.0001$ & $0.82(0.75$ to 0.91$)$ \\
\hline Number of strokes & 21 & 22 & 19 & 16 & 12 & & \\
\hline Relative rate ${ }^{\star}$ & 1 & $1.16(0.64$ to 2.11$)$ & $0.93(0.50$ to 1.73$)$ & $0.66(0.34$ to 1.26$)$ & $0.54(0.26$ to 1.10$)$ & $\mathrm{p}=0.034$ & $0.70(0.51$ to 0.97$)$ \\
\hline $\begin{array}{l}\text { Relative rate } \\
\text { Ischaemic } \|\end{array}$ & 1 & $1.17(0.64$ to 2.12$)$ & $0.96(0.51$ to 1.80$)$ & $0.68(0.35$ to 1.31$)$ & $0.55(0.27$ to 1.14$)$ & $\mathrm{p}=0.05$ & $0.72(0.52$ to 1.00$)$ \\
\hline Number of strokes & 43 & 47 & 51 & 53 & 45 & & \\
\hline Relative rate ${ }^{\star}$ & 1 & $1.16(0.77$ to 1.76$)$ & $1.17(0.78$ to 1.75$)$ & $1.02(0.68$ to 1.53$)$ & $0.91(0.60$ to 1.39$)$ & $\mathrm{p}=0.16$ & $0.87(0.71$ to 1.06$)$ \\
\hline $\begin{array}{l}\text { Relative rate† } \\
\text { Ill defined }\end{array}$ & 1 & $1.19(0.78$ to 1.80$)$ & $1.21(0.81$ to 1.83$)$ & $1.06(0.71$ to 1.59$)$ & 0.95 (0.62 to 1.45$)$ & $\mathrm{p}=0.21$ & 0.88 (0.72 to 1.08$)$ \\
\hline Number of strokes & 177 & 141 & 122 & 141 & 117 & & \\
\hline Relative rate ${ }^{\star}$ & 1 & $0.89(0.71$ to 1.11$)$ & $0.72(0.57$ to 0.91$)$ & 0.72 (0.58 to 0.90$)$ & $0.66(0.52$ to 0.84$)$ & $\mathrm{p}=0.0001$ & $0.79(0.70$ to 0.89$)$ \\
\hline Relative rate $\nmid$ & 1 & $0.91(0.73$ to 1.13$)$ & 0.77 (0.61 to 0.97$)$ & $0.76(0.61$ to 0.95$)$ & $0.70(0.55$ to 0.89$)$ & $\mathrm{p}=0.0009$ & $0.82(0.73$ to 0.92$)$ \\
\hline
\end{tabular}

*Adjusted for age and sex. †Adjusted for age, sex, smoking, diastolic blood pressure, cholesterol, social class and pre-existing CHD. $¥$ International classification of disease, eighth and ninth revisions (ICD-8) and (ICD-9) codes 430-438; §ICD-8: 430 and 431, and ICD-9: 430-432; || ICD-8: 432-435 and 437, and ICD-9: 433-435. 
different associations with ischaemic and haemorrhagic stroke.

\section{Discussion}

To our knowledge only one other populationbased study has examined the association between height and stroke subtype in men and women. ${ }^{2}$ The results were similar to those reported here but are limited because in that study it was not possible to control for socioeconomic position, an important confounding factor.

In the current study $86 \%$ of the cohort were linked to either a record of hospital admission or a death record. ${ }^{5}$ In a study from a more affluent population around a quarter of deaths occurred in people who had spent little or no time in hospital. ${ }^{6}$ It is therefore probable that in the current cohort, many of the $14 \%$ of participants who were not computer linked may never have been admitted to hospital, indicating that record linkage is close to complete. Misclassification bias related to differential hospital attendance among socioeconomic groups is also unlikely as the majority $(74 \%)$ of people with a stroke were admitted to one hospital, with only small proportions admitted to several other hospitals.

The major weakness of this study is the low proportion of strokes that were accurately classified. However, as haemorrhagic strokes usually account for $10 \%-15 \%{ }^{7}$ of all strokes it is likely, given that almost $10 \%$ of strokes were already so defined and that haemorrhagic strokes are more likely to be accurately diagnosed, that the majority of the ill defined strokes are ischaemic. The relative rates for ill defined stroke, intermediate between those for haemorrhagic and ischaemic stroke, are in agreement with this.

Our findings add to the evidence that early life factors may determine risk of stroke. In a recent Finnish study haemorrhagic stroke was more closely associated with birth weight adjusted for head circumference than ischaemic stroke. ${ }^{8}$ The authors hypothesised that reduced fetal growth, in which the brain is spared through differential shunting of blood at the expense of the trunk, may permanently change the cerebral arterial structure resulting in reduced deposition of elastin and increased risk of hypertension and haemorrhagic stroke. Poor fetal growth was also associated with increased risk of ischaemic stroke, but less than that of haemorrhagic stroke. Persons of tall stature are likely to have had optimal fetal and childhood growth reducing the overall risk of stroke, in particular haemorrhagic stroke. Stroke has been declining throughout the past century and the substantial decline in the incidence of haemorrhagic stroke in the 1960s and 1970s traditionally attributed to use of antihypertensives may also be related to contemporaneous increases in height.

The authors thank Pauline MacKinnon for maintenance of the cohort database.

Funding: these analyses were funded by the Stroke Association and Chest, Heart and Stroke Scotland.

Conflicts of interest: none.

1 McCarron P, Greenwood R, Ebrahim S, et al. Adult height is inversely associated with ischaemic stroke. The Caerphilly and Speedwell Collaborative Studies. I Epidemiol Community Health 2000;54:239-40.

2 Njolstad I, Arnesen E, Lund-Larsen PG. Body height, cardiovascular risk factors, and risk of stroke in middleaged men and women. A 14-year follow-up of the Finnmark Study. Circulation 1996;94:2877-82.

3 Davey Smith G, Hart C, Upton M, et al. Height and risk of Davey Smith G, Hart C, Upton M, et al. Height and risk of
death among men and women: aetiological implications of ssociations with cardiorespiratory disease and cancer mortality. F Epidemiol Community Health 2000;54:97-103.

4 Hawthorne VM, Watt GC, Hart CL, et al. Cardiorespiratory disease in men and women in urban Scotland: baseline characteristics of the Renfrew/Paisley (Midspan) study population. Scott Med 7 1995;40:102-7.

5 Hanlon P, Walsh D, Whyte BW, et al. Hospital use by an ageing cohort: an investigation into the association between biological, behavioural and social risk markers and subsequent hospital utilization. 7 Public Health Med 1998;20:467-76.

6 Himsworth RL, Goldacre MJ. Does time spent in hospital in the final 15 years of life increase with age at death? A poputhe final 15 years of life increase with age at

7 Thrift AG, Donnan GA, McNeil JJ. Epidemiology of intracThrift AG, Donnan GA, McNeil JJ. Epidemiology of int

8 Eriksson JG, Forsen T, Tuomilehto J, et al. Early growth adult income, and risk of stroke. Stroke 2000;31:869-74. 